\title{
General Discussion.
}

The Chairman invited discussion on the group of papers just presented, and he called on Mr. BARNARD to make an announcement.

Mr. J. E. Barnard: The point that I wish to raise will only take a few moments. It is this, that Messrs. Swift, I understand, have quite recently manufactured a series of apochromatic objectives. There is no particular innovation in that, because they have made them for years, but I believe that they admit that in some small particulars they come short of the German standard. They are so conscious of the superiority of these new objectives, however, that they are anxious that a Committee should decide as to whether these new objectives are the equals, and we sincerely hope we may say the superiors, of those of German manufacture. For this purpose, therefore, they have suggested, and after consulting with Sir Robert Hadfield we have agreed, that a Committee should be asked to adjudicate upon them, and therefore Sir Robert Hadfield, as President of the Faraday Society, the Presidents for the time being of the Royal Microscopical Society, the Optical Society, and the Photomicrographic Society, and perhaps such an eminent authority in the application of objectives to metallography as Sir George Beilby and one or two others, are to be asked to go into the question of the actual value of these objectives. I feel quite sure that that is a proposition that will appeal to the meeting for the part it will play, apart from any other question; in perpetuating the work of this Symposium. Therefore, even if the results arrived at are not all we hope, this Committee and its conclusions will form a very valuable connecting link between this Symposium and any succeeding work. I therefore have pleasure in moving that this Committee be authorised to proceed with this question.

Mr. F. Watson Baker (Messrs. W. Watson and Sons): May I enquire whether apochromatic objectives of other English firms can also be included? We have made apochromatic objectives for some years, and are quite willing to submit them.

Mr. Barnard : I should say there is no question about that. The reason I brought this up was that Messrs. Swift are the only ones who submitted objectives under the conditions set out, but if any other firm is in the position to submit some, the Committee will be only too anxious to consider them.

Dr. R. Mullineux Walmsley : I am most interested in this question from the educational side. One of the main questions before the Symposium is the production of microscopes in large quantities, and I venture to suggest that, as Mr. Watson Baker says at the end of his paper, the colleges concerned must give him the necessary 
men for that work. I take that to be an absolute condition if we are to turn out instruments of high precision of this nature in quantity. The key of the situation lies in the inspection room of the factory, and unless the inspection room is adequately staffed with thoroughly trained men, the microscope manufacturers of this country cannot hope to rival what has been done-to which I refer with some diffidence in the presence of the President-in the engineering industry. Every engineer knows that the production of apparatus and machinery by the engineering industry - high-speed steam engines and things like that-has been due to efficient inspection by highly trained men in the inspection department. Parts are made in quantity, and are interchangeable, and the thing to aim at is to take the parts from store and have them fitted together without further adjustment by skilled workmen, and so to produce the finished article or machine. If the inspection department does its duty, we need not fear the competition of America or of France, both of which will be more serious than that of Germany in the near future; we need not fear it at all. The British microscope will then stand before the world and hold its own.

Lieut.=Colonel Gifford: In my experience I have worked out a good many apochromatic combinations, chiefly for telescopes, but I have never found any three glasses which gave a sufficiently long focus for microscopic objectives. That has led me to believe that the so-called apochromatic objectives for microscopes, excellent as they are, are not true apochromatics; I mean lenses which combine foci for three different portions of the spectrum. Whether that is so or not, I do not know, but I have met many people who know something of the subject who confirm me in this opinion.

Instructor-Commander M. A. Ainslie: This matter of the apochromatic objective has been occupying my attention for about 12 years, mainly from the point of view of what they would do in the resolution of very fine structure, and from the point of view of comparison between different types of objective. What put it into my mind to address the meeting was the fact that Mr. Swift just, now was referring to his own objective. Mr. Swift a year or two ago was good enough to send me two $4 \mathrm{~mm}$. objectives, one of which was entirely the equal of a perfect Zeiss $4 \mathrm{~mm}$.; and $\mathrm{I}$ have some knowledge of Zeiss $4 \mathrm{~mm}$. objectives, because I have used 18 of them on the same specimen, and I know that specimen by heart. One of the objectives sent me by Mr. Swift was fully equal to anything that Zeiss had done, but the other one was not. I presume that our English opticians are working, so to speak, to a standard. I know that they can turn out work which is in every way as good as anything that has ever been turned out in other countries; but while Continental opticians seem to have a habit of turning out what I might call objectives of 80 to 85 per cent. perfection, our English opticians seem sometimes to turn out something which is very fine- -95 per cent.- but they often also turn out something which is about 60 per cent. perfection. In my experience in an amateur way, I have tested a very large number of immersion objectives, and of dry objectives with apertures from .4 to .95 . I am 
bound to say that the English and other opticians I have had the pleasure of dealing with have put these lenses at my disposal without stint, but I feel that we want to strike a far higher average of excellence. We do not want 95 per cent. perfection in 10 per cent. of the cases, and the remainder under 60 per cent. We want to strike a 90 per cent. average and depend upon it. I want to mention that point because of apochromatic objectives which $I$ have seen made by English manufacturers. I can single out a $4 \mathrm{~mm}$. of $\mathrm{Mr}$. Swift's, a $4 \mathrm{~mm}$. 85 aperture of $\mathrm{Mr}$. Watson Baker, and a $2 \mathrm{~mm}$. of Mr. Watson Baker. I cannot tell you much about the latter, because I do not know what became of the lens, but it was a very perfect one indeed. I can fully echo any remarks that have been made as to the high quality of possible work of English opticians, but I also should like to mention that I wish they would always do it.

Dr. E. C. Bousfield : The few remarks that I shall make to-night have been prompted by what has already fallen, especially from Mr. Barnard, with regard to apochromatic lenses. I think perhaps my experience of them is longer than that of anyone here, since, in conjunction with my friend, the late Mr. Lees Curties, whose loss so many of us deplore, the first photographs made in this country with Zeiss apochromatic lenses were made in my own house, on a dining-room table, incidentally with the tunnel built up with books between the microscope and the camera, and the result was perfectly satisfactory. I think success in this matter depends comparatively little upon the brasswork, but a great deal upon the glasswork, and almost most of all upon the operator. The apochromatic lenses which were at first supplied were of the finest possible quality. I think I have seen nothing better than the first $2 \mathrm{~mm}$. apochromatic lens which I had from Zeiss, but, unfortunately, as was the case with all these early lenses, the glass was very soon attacked by the atmosphere, and in substituting a glass which was more resistent, the qualities of the lens suffered very considerably, and when it was returned to me the field was very much less flat than it had been in the first instance. There is one maker who has not been referred to to-night, but who was absolutely, I believe, the pioneer of apochromatic lens work in this country-I mean the firm of Powell and Leeland. Certainly they turned out-and I say it without any disrespect to anyone else. - the very finest work in the shape of glasswork that has ever been used in the world, and British glass-work has been of remarkable excellence. They supplied me, for trial, with an apochromatic lens of their own manufacture, which was calculated in England and made in England, and it was absolutely perfect, but it had the same fault that the Zeiss lenses had, in being made of unstable glass. None of the $2 \mathrm{~mm}$. lenses that $\mathrm{I}$ have seen made of the more resistent glass are at all free from roundness of field. I notice that in one of the papers that is to be laid before us reference is made to this roundness of field, and in actual working, those of us who have tried it with, say, 1,000 diameters, will agree that it is a very serious trouble indeed, and I do not see any way of getting over it. Lower magnification and a longer camera does not do so. I suppose the reasons are mathernatical ones, which are beyond me. 
I can only state the fact that if you get the same magnification with, say, a $\frac{1}{2}$-inch lens and a long camera that you were getting with a $\frac{1}{4}$-inch lens and a short camera, you will hardly get more flatness of field in the one case than in the other.

There is just one other point, and that is that in all the photomicrographic apparatus which I have seen and possessed, there is one fault which seems to be inseparable from the instruments, and that is, with an extended camera, the connection between the operator and the focussing portion of the microscope, especially with lateral focussing milled-heads. These are extremely convenient, no doubt, for bench work in the laboratory, but for ordinary purposes of photomicrography it is extremely difficult to connect them satisfactorily with any form of extended focussing arrangement, and in any photomicrographic apparatus which may be put forward that point should certainly be kept in mind. The most efficient contrivance, I think, that I have ever seen-and the hint may be of use to some here, perhaps-was that of my friend, Dr. Neuhauss, of Berlin, who was well known as one of the very first photomicrographers in Germany. He simply carried a straight arm down from the axial focussing head of the fine adjustment, and attached a string to the lower end, with a weight on one side and a drum on the other, and so he managed to get his focussing fairly accurate. In conversation with Dr. Czapski once, when he came to see me, I pointed out to him that I found it impossible to get accurate focussing without tapping the bench, to make sure that the last adjustment was as delicate as possible, and he said, "Oh, that is quite the regular way for giving the final touch in delicate measurement" ; so that I presume I had not gone very far wrong.

Lieut.=Colonel Gifford : I have in my possession two of these early Zeiss lenses. The late Mr. C. Lees Curties procured them for me at a very early period. One is marked No. 2, and is a $6 \mathrm{~mm}$. of $0.95 \mathrm{~N} . \mathrm{A}$., and the other is a $3 \mathrm{~mm}$. of $1.40 \mathrm{~N}$.A., and is marked No. 34. Neither of them have suffered in the slightest, and I use them to-day as well as I did originally. On the other hand, I have Powell objectives. One of them is a $1 / 10$ of 1.5 N.A.-a very large aperture indeed-and the other is $1 / 20$ of the same N.A. The $1 / 10$ became entirely obscured about two or three years ago. That, however, has been renovated by the present Mr. C. Lees Curties. The other one, the $1 / 20$, has stood all through. At the same time, if you compare the two makers, I am afraid we must prefer the Zeiss. Both lenses which I possess of that make are simply perfect; I suppose they could not be quite perfect, but they are as perfect as they possibly can be. They stand any power you like to apply to them.

Dr. W. Rosenhain, F.R.S.: I want to draw attention to one particular point about the discussion which has impressed itself upon me in listening to it, and that is that there seem to be two totally distinct questions being discussed in a rather confused manner. The one is the question of establishing a commercial and industrial production of microscopes by mass production. This is, no doubt, a very excellent and valuable industrial step, with which, of course, 
every sympathy, and I wish it every success, and shall be glad to do anything to assist it. That is one thing, but the progress of the microscope as an instrument of research and an instrument of precision is quite another thing, and we must not forget the one in view of the other. It was particularly gratifying to find that whilst two of our manufacturing friends were good enough to come here this evening and to speak almost entirely of mass production, the third gave us some prospect of work which was directed towards achieving the best possible that could be achieved, and I hope that it will not only receive the acknowledgment which $I$ am sure it will deserve at the hands of all users of the microscope, but that all manufacturers will feel, I think I may say, that it is their duty, to look after that side of the thing, just as much as to send out a cheap microscope by the thousand; I hope they will succeed in both.

\section{Mr. A. C. Banfield (Communicated).}

War considerations and other matters have prevented any active participation on my part in things microscopical for the last five years, yet, once having used a microscope, it is impossible entirely to lose one's interest in this important aid to scientific research.

One of the main objects of this Symposium is to suggest possible means of improvement to this instrument, and I will confine my remarks entirely to certain points which have occurred to me at various times.

(1) It is the custom at present, in all high grade microscopes, to supply them with two slides, which carry respectively the coarse and fine adjustments. This is an expensive form of construction, and as I am one of those persons of opinion that very little is mechanically impossible, it should be possible to eliminate one of these slides, making the single slide do duty for both adjustments. Also, as constructed at present, the fine adjustment slide is nearest to the limb, thus causing the delicate micrometer screw or lever to carry the weight of the parts necessary to operate the coarse movement in addition to that of the body tube-the only part the fine adjustment should move.

(2) It is hard to explain the preference which undoubtedly exists in this country for the tripod foot, rightly termed the " English" foot, for it exists in no other country. Many English manufacturers enthuse on " the beautiful hand work" to be found in their instruments, and I imagine that the tripod foot is especially designed to show this off. Now the universal trend in all modern manufacturing is to eliminate entirely all possible hand work; nothing adds more to the total cost of any article than operations which have to be carried out entirely by hand. My indictment of the tripod foot is that it is of a shape which is difficult to cast, and impossible to machine. It is, furthermore, very bulky, and seriously interferes with the efficient operation of the sub-stage when the microscope is in a vertical position. A greater rigidity is claimed for this foot; this certainly is correct if one wants to lean on the instrument, otherwise there is no advantage over the horse-shoe foot, resting on its three milled pads. 
(3) In most microscopes that I have used, the slides have been located in a position too near to the stage; the Continental makers are the worst sinners in this respect. The result of this practice is that when an object is focussed, the body tube has to be very considerably racked out, so that the slides only engage for about a third to half of their possible bearing. This does not add to the rigidity. The instrument should, of course, be designed in such a manner that with an objective in place on a changer, and focussed on an object, the male and female elements of the slide should be in complete engagement throughout their length.

(4) Even at the present state of mechanical advance, makers are still to be found preaching the virtues of the sprung slide. In the whole world of mechanics there is no more horrible device than this. It is supremely inaccurate and unreliable, and is merely adopted as an expedient to cover a state of residence in the dark ages of mechanics. Incidentally, I may remark, there seems a strange disinclination on the part of instrument makers to adopt modern manufacturing methods, the broaching machine, with the wonderful possibilities it holds out in the direction of dovetail and other slides, and eye-piece fittings appear to be quite unknown. Again, take such a simple job as a body tube. The common practice is to skim this in a bench lathe, then with the aid of a file and French cloth bring it to the lacquering stage-a tedious job, taking quantum sufficit, according to the workman. The whole job can be done on a modern grinder in a minute and a-half.

(5) Regarding the oblique illumination of metallographic specimens under high powers, it occurs to me that advantage may occur by reviving that old idea of fifty years ago in a modern form. If a glass rod, say a quarter of an inch in diameter and four inches long, is taken, and the ends squared and polished, it will serve to convey light from a source to an object with practically no loss. One end may almost touch an open arc, for instance, thus gathering rays at a high angle. These rays are carried along the rod by internal reflection (there is no need to silver the rod externally), emerging at the far end in a beautifully diffused bunch. This is no novelty to most of you, but I suggest that a variation of this idea may be of use in metallography. Take a worked slip, like a small Lummer plate, say $4 \mathrm{~mm}$. wide and $\frac{1}{2} \mathrm{~mm}$. thick. On one end balsam a hemi-cylindrical lens of 3 or $4 \mathrm{~mm}$. radius. The other end can be introduced well under an immersion objective, not quite under but probably far enough. For this purpose, the slip would have to be silvered, except at the ends, otherwise the light would leave the slip at the first contact with the oil. At the other end, parallel rays are directed from some powerful source. I merely suggest this expedient for your consideration, as there appears to be a necessity for it at times.

(6) I have no practical acquaintance with metallography, but a specimen was sent to me a few days ago by a Sheffield firm. Now this specimen is distinctly spherical, and if specimens of this description are the rule and not the exception, $I$ do not wonder that 
complaints " that the objective has not a flat field" are so common. The objective is computed for a mathematically flat object; if the specimen deviates from a true plane, then definition is bound to suffer. I merely refer to this point because it suggested to me an idea which it may profit some capable mathematician to investigate, which, briefly, is this :

It is just as easy to prepare a metal specimen, worked to a definite radius, as it is to work it to a plane. Unfortunately, I am not a mathematician, but I suggest that by adopting some small concave radius for a metal specimen, say $10 \mathrm{~mm}$., it may be possible greatly to improve the metallographic objective. The improvement may possibly take the form of a greatly simplified construction, or it may prove a means of increasing the N.A. of a lens. Personally, were I capable of it, I should compute it first of all unachromatised for use with the well-known Mercury line 5461, a powerfuI source of monochromatic light easily isolated. It could, if it showed promise, be further computed (all fluorite construction) for the powerful ultra-violet radiation at 1851 . This would bring the N.A. for a $2 \mathrm{~mm}$. lens to somewhere about 3.5 .

(7) I have suggested the above (under 6) as a possible source of an improved objective for metallurgical purposes, but by working a specimen to a radius, it is possible to compensate an apochromatic or other objective which lacks flatness of field, by applying the wellknown sphereometer formula.

Take a ruled stage micrometer, focus the centre of the field, and note reading on micrometer drum of the fine adjustment, after which take the reading of the alteration necessary to render the lines at the edge of the field sharp. Then if $\mathbf{S}$ is the semi-diameter of the circle in the object plane represented by the field of view, we can immediately say that if the object be given a curvature whose radius is

$$
\mathrm{R}=\frac{\mathrm{S}^{2}}{2 d}
$$

the field of view will be in focus simultaneously at the centre and margin. $d$ is, of course, the difference between the two readings of the fine adjustment drum.

A further group of papers dealing with various general aspects of microscope design and construction, presented by M. Eugene Schneider, Professor Alexander Silverman, Dr. R. E. Slade and Mr. G. I. Higson, and Mr. R. J. E. Hanson were taken as read. 